\title{
Emotional potential in the children's team
}

\author{
Tetyana I. Svatenkova, Oleksandr V. Svatenkov
}

Mykola Gogol Nizhyn State University, Nizhyn, Ukraine

\begin{abstract}
Introduction. Increased interest in the study various groups that perform joint activities in social, organizational, economic, sports psychology and work psychology nowadays. The urgency is: the fast changing forms of work organization based on the high economic interest and responsibility all members of the group; relative production-economic and organizationalmanagerial independence of labor collectives, which contributes to the self-organization development and self-government forms improvement; the team fitness issue is becoming more and more relevant.
\end{abstract}

Purpose. The purpose of the paper is to investigate the group psychological work influence on the children emotional intelligence development and the processes of psychological stability and cohesion in a sport team.

Methodology. We used the comprehensive diagnosis of the child's personality and status in the group ( $n=622$ ). The main accent was made on the level of emotional intelligence (EQ) and sociometric status of the child. The main hypothesis: the higher the child's EQ level, the higher its sociometric status. The standard PASW Statistics method was used to process the statistics.

Results. Sociometric tests: 223 children had a low sociometric status (36\%); 242 - satisfactory and within the norm limits (39\%), 75 - above the average (12\%), and only 81 had a high sociometric status (13\%). The EQ level indicators (integrative level): 317 respondents had a low EQ level (51\%); 218 - the average level (35\%) and only 87 respondents had a high El level (14\%).

Conclusions. After the implementation of the author's program for adaptation and the child emotional intelligence development, we have results: Sociometric test: only 56 children have lower sociometric status (9\%); 144 - satisfactory and average (23\%); 223 - above average (36\%) and 199 - high sociometric status (32\%). EQ level (integrative level), we also have positive changes: only 111 respondents remained with a low level of emotional intelligence (18\%); 386 developed the level of emotional intelligence to the average (62\%) and 125 had a high level of emotional intelligence (20\%)

\section{Keywords}

mental health, emotional intelligence, interpersonal relationships, cohesion.

\footnotetext{
Address for correspondence:

Dr. Tetyana I. Svatenkova, PhD, Associate Professor of the Department of General and Practical Psychology, Mykola Gogol Nizhyn State University, Nizhyn, Ukraine.

e-mail: tatianasvatenkova@gmail.com

This work is licensed under a Creative Commons AttributionNoncommercial 4.0 International License (CC BY-NC 4.0).

(c) (1) (2)

(C)Copyright: Svatenkova, 2021

Licensee NDSAN (MFC- Coordinator of the NDSAN), Italy

DOI: https://dol.org/10.32437/mhgcj.v4i2.110
}

Submitted for publication: 12 March 2021

Received: 12 March 2021

Accepted for publication: 26 July 2021 